\title{
An Investigation into Listening Comprehension Strategies and the Relationship between Listening Comprehension Strategies and Overall Proficiency Level of Intermediate and Advanced Learners
}

\author{
Ali Kazemi \\ Dept. of English, College of Humanities, Yasouj University, Iran \\ Soraya Kiamarsi \\ Dept. of English, College of Humanities, Yasouj University, Yasouj, Iran
}

\begin{abstract}
Research into the role of listening strategies in acquiring knowledge of language has attracted increasing attention over last decades. The current study sought to determine the strategies used by intermediate and advanced learners. It also attempted to investigate the relationship between learners' overall language proficiency and their choice of strategy. To this end, two language institutes were randomly selected in Yasouj. A Quick Placement Test was validated and administered. Based on the results, 30 intermediate and 30 advanced EFL learners were selected. Two listening tasks were given to each group. Think-aloud technique was used in order to elicit learners' listening strategies. The protocols were coded by two raters in order to yield more reliable results. The data analyzed through descriptive statistics showed that advanced learners employed more listening comprehension strategies than intermediate listeners did. It was shown that advanced learners employed meta-cognitive strategies more frequently than cognitive and socio-affective strategies. However, intermediate language learners employed cognitive, and then social/affective strategies more frequently. The findings of the present study indicated that there was a relationship between overall listening proficiency of language learners and listening strategies employed by them.
\end{abstract}

Index Terms - listening strategies, think-aloud technique, overall proficiency, listening comprehension

\section{INTRODUCTION}

Listening was a long-neglected aspect of language learning not only in research, but also in language classrooms because it was assumed that it is acquired automatically without much effort. In addition, Rost (1990) showed that language teachers do not have enough knowledge about listening strategies, and therefore, they do not tend to teach them in the classroom.

The importance of listening ability is increasing in the world, and technological advances in global communication have made listening by non-natives even more vital (Mendelsohn, 1998). Wolvin and Coakley (1988) showed that listening consumes more of daily communication time than other forms of verbal communication, both in and out of the classroom. Vandergrift also showed that in daily life, people spend $40-50 \%$ of their communication on listening (Vandergrift, 1999). Therefore, it is necessary for students who learn English as a second or foreign language to improve their learning abilities of listening. Over these last decades, listening has attracted growing interest in foreign or second language learning, leading teachers to look for new and most importantly practical methods to maximize the efficiency of their listening instruction in both EFL and ESL settings.

Learning listening is difficult because listeners have to use their knowledge of the second language and their background knowledge in order to interpret the oral input (Young, 1997); hence the language learners have to rely on some listening strategies. Chamot (2004) defined these learning strategies as "the conscious thoughts and actions that learners take in order to achieve a learning goal" (p. 14). According to Cohen (2010), these learning strategies are part of "Individual differences" (IDs) that refer to 'personal baggage' which learners bring to the classrooms. These Individual differences include some factors such as anxiety, age, personality, aptitude, gender, motivation, attitudes, beliefs, and learning strategies. Vandergrift (1999) stated that learners have to make use of listening strategies in order to guide and monitor their listening comprehension.

Improving listening ability contributes in significant ways to learning a foreign language; learners have to make use of some strategies in order to succeed in the process of listening comprehension. However, little attention has been paid to the choice of these strategies by learners with different language proficiency levels; hence, a better understanding of 
these strategies and the way they are employed by learners are of high importance. Therefore, this study sought to determine the strategies used by learners with different overall language proficiency (intermediate and advanced), and to investigate the relationship between learners' overall language proficiency and their choice of strategy.

\section{REVIEW OF LITERATURE}

Interest in language learning strategies (behaviors that learners engage in to learn a second/foreign language) emerged with the work of Rubin (1975) with the curiosity of identifying "what a good language learner does". It was at that time that the notion that learner strategies and techniques might assist second language acquisition appeared. Rubin (1975) stated that "good language learner" might do something different that we could all learn from. Rubin (1975) identified some strategies used by good learners and asserted that language teachers can train poor learners using these strategies. Besides, she emphasized the vital role of these strategies as a means to help the students help themselves, in the absence of the teacher. According to Fedderhold (1997), the language learner who is able to use a wide variety of language learning strategies appropriately can expand his language skills in a better way. Lessard-Clouston (1997) stated that language learning strategies can help the students develop their communicative competence.

Different taxonomies for listening comprehension strategies have been provided by researchers. For example, Oxford (1990) divided these strategies into direct (cognitive, memory, and compensation) and indirect (strategies which do not affect the language tasks directly including metacognitive, affective and social) strategies (Oxford, 1990).

Rubin (1989) classified language learning strategies into two main categories (strategies that have a direct effect on learning, and processes that directly influence leaning) and a number of subcategories (clarification/verification, monitoring, memorization, guessing/inductive inferencing, deductive reasoning, practice, processes which create opportunities for practice, and production tricks). The taxonomy presented by O'Malley and Chamot (1990) is one of the widely used classifications. They believe that language entails active and dynamic mental processes and thus classify learning strategies into three major categories: metacognitive strategies, cognitive strategies and social/affective strategies. Metacognitive strategies help learners to plan for the coming learning tasks, monitor the process, and then assess the output after the completion of the learning activity. Cognitive strategies are tools by which learners can solve the learning problems or complete the learning task during the process of manipulating the target language. Social/affective strategies are those strategies which are mainly concerned with cooperative learning. Language learners use these strategies in order to reach a common goal and ask questions for clarification and self-talk to redirect thoughts (O’Malley \& Chamot, 1990). Their classification is comprehensive and reasonable in that they combine learning strategies with learners' knowledge processing.

\section{METHOD}

\section{A. Participants}

Through random sampling, two language institutes were chosen out of the language institutes in Yasouj. A Quick Placement Test which is given in the Appendix was administered to those who were believed to be at the intermediate and advanced level of proficiency. The test includes 60 items. The test was given to 110 learners. The results are given in Table 3.

Based on the results of the test, 30 intermediate and 30 advanced learners were chosen through purposive sampling as the participants of the study.

\section{B. Instrument}

OPT was used in order to categorize the learners into intermediate and advanced learners. Then some listening comprehension tasks were given to participants in order to elicit the required information about learners' listening strategies. The tasks were not too long, and they did not contain technical terminologies. The tasks used for eliciting advanced learners' strategies were selected from TOEFL tests. Two other tasks were taken from Four Corners, a book which is taught in Yasouj language institutes, for intermediate group.

\section{Data Collection Procedure}

A proficiency test was administered to categorize the participants into advanced and intermediate groups. Then some listening comprehension tasks were given to participants in order to elicit the required information about learners' listening strategies. The tasks were not too long, and the content was not technical. They were selected from TOEFL tests, and one of the books which is taught in some language institutes, namely Four Corners.

Learners may use different strategies while doing a listening task. But they may not be able to remember the strategies at the end of the task; hence, think-aloud technique was used. Using think-aloud method, we were able to reach a quite unbiased insight into the participants' listening processes and strategies. Sixty sessions were undertaken; one session for each participant. According to Ericsson and Simon (1984), learners should be taught to verbalize "all" their thoughts immediately and without selection. All sessions were audio-recorded. Participants were allowed to use their first language to think aloud. Each participant was asked to listen to the selected task. And the researcher tried to elicit their listening strategies implicitly. 
Before answering to the questions, we asked each participant to listen to the task again. Then participants were asked to tell everything they remembered about the task. Then the protocols were coded using a predefined taxonomy of listening comprehension strategies (O'Malley and Chamot, 1990). This taxonomy is divided into three main categories: metacognitive strategies, cognitive strategies and social/ᄀaffective strategies. Metacognitive strategies help learners to plan for the coming learning tasks, monitor the process, and then assess the output after the completion of the learning activity. Cognitive strategies are tools by which learners can solve the learning problems or complete the learning task during the process of manipulating the target language. Social/affective strategies are those strategies which are mainly concerned with cooperative learning. This classification is comprehensive and reasonable in that they combine learning strategies with learners' knowledge processing. To assess the reliability of the coding scheme, two raters categorized all the protocols independently. Inter-rater reliability was calculated as 85\%. Most of the disagreements were resolved through discussion. The rate of agreement after discussion was about $97 \%$.

\section{Data Analysis Procedure}

The current study sought to uncover the listening strategies used by intermediate and advanced language learners, and to investigate the relationship between learners' overall language proficiency and their choice of strategy. Descriptive statistics was carried out to determine the students' listening strategies as revealed through the think-aloud protocol technique and the EFL listening comprehension test. The data obtained from the think-aloud protocols were analyzed by making use of qualitative content analysis. In order to reveal whether there is a significant relationship between the students' overall language proficiency and their choice of listening strategy, descriptive analysis was carried out.

\section{FINDINGS}

\section{A. Listening Strategies Adopted by Intermediate Language Learners}

The first research question was about the strategies used by intermediate language learners. The learners were given two tasks from a book which is taught in some language institutes, namely Four Corners. Then, they were asked to think-aloud, which required them to verbalize their thoughts while doing the task. The protocols were recorded for later transcription. Following that, the protocols were coded by two raters using a predefined taxonomy by O'Malley and Chamot (1990). The taxonomy includes three main categories (metacognitive, cognitive, and social/affective) and some subcategories.

TABLE 1.

INTERMEDIATE LEARNERS' STRATEGY USE IN 2 DIFFERENT TASKS

\begin{tabular}{|l|l|l|l|l|}
\hline & Task 1 & Task 2 & Percentage \\
\hline & Frequency & Percentage & Frequency & $15.38 \%$ \\
\hline Metacognitive & 5 & $11.90 \%$ & 6 & $69.23 \%$ \\
\hline Cognitive & 31 & $73.80 \%$ & 27 & $15.38 \%$ \\
\hline Social/Affective & 6 & $14.28 \%$ & 6 & 39 \\
\hline Total & 42 & $100 \%$ & 39 & $100 \%$ \\
\hline
\end{tabular}

As it can be seen, intermediate language learners used more cognitive strategies than metacognitive and social/affective strategies in both tasks. The table shows that the total number of strategies used in both tasks is almost equal (42 strategies in Task 1 and 39 strategies in Task 2). In addition, the frequency of metacognitive and social/affective listening strategies of intermediate language learners was nearly equal in both tasks. However, intermediate learners used more cognitive strategies in Task 1 than Task 2 (73.80\% in Task 1 vs. 69.23\% in Task 2).

The following table shows the frequencies and percentages of the use of the main categories of listening strategies by intermediate language learners. In this case, no distinction was made between the two tasks.

TABLE 2.

INTERMEDIATE LEARNERS' STRATEGY USE REGARDLESS OF DIFFERENT TASKS

\begin{tabular}{|l|l|l|}
\hline & Frequency & Percentage \\
\hline Cognitive & 58 & $71.60 \%$ \\
\hline Metacognitive & 11 & $13.58 \%$ \\
\hline Social/Affective & 12 & $14 \% 81$ \\
\hline Total & 81 & $100 \%$ \\
\hline
\end{tabular}

Of all the listening strategies used by intermediate language learners, $71.60 \%$ accounted for cognitive strategies, $14.81 \%$ for social/affective strategies, and $13.58 \%$ for metacognitive strategies. It could easily be seen that intermediate learners used cognitive strategies more frequently. These frequencies are given in the following chart.

O'Malley and Chamot (1990) subdivided the three main categories of listening strategies, i.e., metacognitive, cognitive, and social/affective, into some subcategories. Metacognitive category was subdivided into advance organizers, directed attention, selective attention, self-management, self-reinforcement, self-monitoring, and selfevaluation. Social/affective category includes cooperation and techniques for lowering anxiety; however, the last category is represented by the title of the main category (i.e., social/affective). Cognitive category is subdivided into 
resourcing, repetition, grouping, deduction, imagery, auditory representation, transfer, recombination, translation, key word, elaboration, inferencing, note-taking, and summarizing. The frequency of subcategories regardless of the tasks is presented in Table 3.

The following table provides the information related to the frequency and percentage of strategy use by intermediate learners.

TABLE 3.

FREQUENCY OF STRATEGIES USED BY INTERMEDIATE LEARNERS

\begin{tabular}{lll}
\hline & Frequency & Percentage \\
\hline advance organizers & 1 & $1 / 23$ \\
\hline directed attention & 1 & $1 / 23$ \\
selective attention & 1 & $1 / 23$ \\
self-management & 4 & $4 / 93$ \\
self-reinforcement & 0 & 0 \\
\hline self-monitoring & 1 & $1 / 23$ \\
\hline self-evaluation & 3 & $3 / 70$ \\
\hline Social/affective & 12 & $14 / 81$ \\
\hline Resourcing & 2 & $2 / 46$ \\
\hline Repetition & 2 & $2 / 46$ \\
Grouping & 0 & 0 \\
\hline Deduction & 3 & $3 / 70$ \\
\hline Imagery & 4 & $4 / 93$ \\
\hline auditory representation & 1 & $1 / 23$ \\
Transfer & 3 & $3 / 70$ \\
\hline Recombination & 5 & $6 / 17$ \\
Translation & 10 & $12 / 34$ \\
\hline key word & 4 & $4 / 93$ \\
\hline Elaboration & 4 & $4 / 93$ \\
\hline Inferencing & 2 & $2 / 46$ \\
\hline note-taking & 16 & $19 / 75$ \\
\hline Summarizing & 2 & $2 / 46$ \\
Total & 81 & $100 \%$ \\
\hline
\end{tabular}

The above table shows the frequency and the percentage of strategy use by intermediate language learners. It could be seen that the total number of strategy use by intermediate learners was 81 . The most frequently used strategies by intermediate language learners were note-taking and translation, which are subcategories of cognitive strategies, and social/affective strategies. Of all the 81 listening strategies, note-taking accounted for $19.75 \%$, translation for $12.34 \%$, and social/affective for $14.18 \%$. The least frequently used strategies were advance organizers, directed attention, selfmonitoring and self-reinforcement, which are subcategories of metacognitive strategies, and grouping and auditory representation, which belong to cognitive category. Of all the listening strategies used by intermediate language learners, $71.60 \%$ accounted for cognitive strategies, $14.81 \%$ for social/affective strategies, and $13.58 \%$ for metacognitive strategies.

The table shows that the highly preferred listening strategies by intermediate group were note-taking (19.75\%), translation (12.34\%), and social/affective (14.18\%). The first two subcategories belong to cognitive category. The least frequently used subcategories were mostly in metacognitive group (for example self-reinforcement, advance organizers, and selective attention).

\section{B. Listening Strategies Adopted by Advanced Language Learners}

In the second research question, the researcher tried to discover the advanced learners' listening strategies through think-aloud protocol. The same procedure was followed to answer this question. The learners in this proficiency group were given two tasks from TEFL tests. The researcher asked them to verbalize their thoughts. Again two raters coded the protocols in order to yield more reliable findings. Disagreements about the raters' coding scheme were solved through discussion. As it was said before, the protocols were coded based on a predefined taxonomy developed by O'Malley and Chamot (1990). The taxonomy includes three main categories (i.e., metacognitive, cognitive, and social/affective) and some subcategories. The numerical data of the frequency of these strategies by advanced language learners is presented in the following table.

The distinction between advanced learners' strategy use in terms of the tasks given is presented in the following table.

TABLE 4.

ADVANCED LEARNERS' STRATEGY USE IN 2 DIFFERENT TASKS

\begin{tabular}{|l|l|l|l|l|}
\hline & Task 1 & Task 2 & Percentage \\
\hline & Frequency & Percentage & Frequency & $74 \%$ \\
\hline Metacognitive & 41 & $70.68 \%$ & 37 & $24 \%$ \\
\hline Cognitive & 16 & $27.58 \%$ & 12 & $2 \%$ \\
\hline Social/Affective & 1 & $1.73 \%$ & 1 & 50 \\
\hline Total & 58 & $100 \%$ & 50 & $100 \%$ \\
\hline
\end{tabular}


The table reveals that advanced language learners used more metacognitive strategies than cognitive and social/affective in both tasks. The table also shows that the learners used more strategies in Task 1 (58 strategies in Task 1 and 50 strategies in Task 2). In addition, the frequencies of metacognitive and cognitive listening strategies of advanced language learners were different in both tasks. However, the use of social/affective strategies was equal in both tasks.

The following table shows the frequencies and percentages of the use of the main categories of listening strategies by advanced language learners. In this case, no distinction was made between the two tasks.

TABLE 5.

ADVANCED LEARNERS' STRATEGY USE REGARDLESS OF DIFFERENT TASKS

\begin{tabular}{|l|l|l|}
\hline & Frequency & Percentage \\
\hline Cognitive & 78 & $72.22 \%$ \\
\hline Metacognitive & 28 & $25.92 \%$ \\
\hline Social/Affective & 2 & 1.85 \\
\hline Total & 108 & $100 \%$ \\
\hline
\end{tabular}

Of all the listening strategies used by advanced language learners, 72.22\% accounted for cognitive strategies, $25.92 \%$ for cognitive strategies, and only $1.85 \%$ for metacognitive strategies. According to the table, advanced learners preferred to use metacognitive strategies more frequently.

As it was said before, each of these strategies has some subcategories. The frequency of the use of the abovementioned subcategories in the 2 tasks is illustrated in the following table.

TABLE 6.

NUMERICAL DATA OF THE FREQUENCY OF STRATEGIES USED BY ADVANCED LEARNERS

\begin{tabular}{lll}
\hline & Frequency & Percentage \\
\hline advance organizers & 7 & 6.46 \\
\hline directed attention & 2 & 1.85 \\
selective attention & 8 & 7.40 \\
self-management & 18 & 16.66 \\
\hline self-reinforcement & 14 & 12.96 \\
\hline self-monitoring & 20 & 18.51 \\
self-evaluation & 9 & 8.33 \\
\hline Social/affective & 2 & 1.85 \\
Resourcing & 0 & 0 \\
Repetition & 0 & 0 \\
Grouping & 0 & 0 \\
Deduction & 1 & 0.92 \\
Imagery & 2 & 1.85 \\
\hline auditory representation & 0 & 0 \\
Transfer & 2 & 1.85 \\
recombination & 3 & 2.77 \\
\hline Translation & 9 & 8.33 \\
key word & 0 & 0 \\
\hline Elaboration & 1 & 0.92 \\
Inferencing & 2 & 1.85 \\
\hline note-taking & 8 & 7.40 \\
Summarizing & 0 & 0 \\
\hline Total & 108 & $100 \%$ \\
\hline & & \\
\hline & 0 & \\
\hline
\end{tabular}

The total number of strategies used by advanced learners was 108, which is more than the total numbers of the used strategies by intermediate learners. The most frequent strategies in this group were self-management, self-reinforcement, and self-monitoring, all of which belong to metacognitive category. Of all the 104 listening strategies used by this group, self- monitoring accounted for $18.51 \%$, self-management accounted for 16.66, and self-reinforcement strategies accounted for $12.96 \%$. The least frequently used strategies were summarizing, elaboration, key word, auditory representation, grouping, repetition, and resourcing which are subcategories of cognitive strategies. The most frequently used cognitive strategies by advanced learners were note-taking (7.40\%) and translation (8.33\%). Of all the listening strategies used by advanced language learners, $72.22 \%$ accounted for cognitive strategies, $25.92 \%$ for cognitive strategies, and only $1.85 \%$ for metacognitive strategies. Thus, advanced learners tended to use metacognitive strategies more often.

\section{The Relationship between Language Learners' Overall Proficiency and Their Choice of Strategy}

As it was mentioned, language learners have to rely on some strategies in order to comprehend listening tasks. This study aimed at investigating the relationship between language learners' overall proficiency and their choice of strategy. The frequency of strategies used by intermediate and advanced groups is presented in the following tables and charts. 
TABLE 15.

NUMERICAL DATA OF THE FREQUENCY OF STRATEGIES USED BY INTERMEDIATE LEARNERS

\begin{tabular}{lll}
\hline & Frequency & Percentage \\
\hline advance organizers & 1 & $1 / 23$ \\
directed attention & 1 & $1 / 23$ \\
\hline selective attention & 1 & $1 / 23$ \\
self-management & 4 & $4 / 93$ \\
self-reinforcement & 0 & 0 \\
\hline self-monitoring & 1 & $1 / 23$ \\
\hline self-evaluation & 3 & $3 / 70$ \\
\hline social/affective & 12 & $14 / 81$ \\
Resourcing & 2 & $2 / 46$ \\
\hline Repetition & 2 & $2 / 46$ \\
Grouping & 0 & 0 \\
\hline Deduction & 3 & $3 / 70$ \\
Imagery & 4 & $4 / 93$ \\
\hline auditory representation & 1 & $1 / 23$ \\
Transfer & 3 & $3 / 70$ \\
Recombination & 5 & $6 / 17$ \\
Translation & 10 & $12 / 34$ \\
\hline key word & 4 & $4 / 93$ \\
Elaboration & 4 & $4 / 93$ \\
\hline Inferencing & 2 & $2 / 46$ \\
note-taking & 16 & $19 / 75$ \\
\hline Summarizing & 2 & $2 / 46$ \\
Total & 81 & $100 \%$ \\
\hline
\end{tabular}

The above table shows that most frequently-used strategies by intermediate group are note-taking (19.75\%), translation (12.34\%), and social/affective (14.81). They used translation frequently. Learners in this group did not use metacognitive strategies frequently. The frequency of these strategies was 11 out of 81 . Although intermediate learners used cognitive strategies more, some of these strategies were not used at all, and the frequency of some others was very low. Examples are grouping and auditory representation. The table shows that the intermediate learners tended to use social/affective strategies, as well. They worked with one or more peers to obtain feedback or pool information. So, it can be concluded that the most preferred strategies by intermediate language learners were cognitive and social/affective strategies.

TABLE 16.

NUMERICAL DATA OF THE FREQUENCY OF STRATEGIES USED BY ADVANCED LEARNERS

\begin{tabular}{lll}
\hline & Frequency & Percentage \\
\hline advance organizers & 7 & 6.46 \\
directed attention & 2 & 1.85 \\
selective attention & 8 & 7.40 \\
\hline self-management & 18 & 16.66 \\
self-reinforcement & 14 & 12.96 \\
self-monitoring & 20 & 18.51 \\
self-evaluation & 9 & 8.33 \\
social/affective & 2 & 1.85 \\
Resourcing & 0 & 0 \\
Repetition & 0 & 0 \\
Grouping & 0 & 0 \\
Deduction & 1 & 0.92 \\
Imagery & 2 & 1.85 \\
\hline auditory representation & 0 & 0 \\
Transfer & 2 & 1.85 \\
Recombination & 3 & 2.77 \\
Translation & 9 & 8.33 \\
\hline key word & 0 & 0 \\
\hline Elaboration & 1 & 0.92 \\
\hline Inferencing & 2 & 1.85 \\
note-taking & 8 & 7.40 \\
\hline Summarizing & 0 & 0 \\
Total & 108 & $100 \%$ \\
\hline
\end{tabular}

One of the highly-used strategies by advanced group was self-management. The learners in this group tried to arrange the appropriate conditions for learning. They also checked and corrected their comprehension while the listening task was taking place (self-monitoring strategy). It appears that advanced learners are more able to verify continually and correct their comprehension as they are listening. Self-reinforcement was another frequent strategy used by these learners. It should be mentioned; however, that advanced learners used some cognitive strategies, as well; especially translation and note-taking. The results suggest that participants in both groups often use their native language to help with EFL listening comprehension. It is worth noting that only two of the participants in advanced group used social/affective strategies. 
Therefore, the results demonstrated that advanced learners employed a wide variety of metacognitive strategies, while the most favored listening strategies for learners in the intermediate group were cognitive, and then social/affective strategies.

\section{DISCUSSION}

This study aimed to find out the strategies employed by intermediate and advanced language learners, and to explore whether there was a relationship between the strategies employed by these groups and their overall proficiency levels.

The results of the study suggest that both intermediate and advanced learners appear to be familiar with a wide range of strategies. However, the findings of the study show that advanced learners employed more listening comprehension strategies than intermediate listeners did. This finding implies that the difference in listening proficiency between intermediate and advanced learners seems to be related to the quantities of listening strategies they employed. The use of listening strategy does not guarantee success in listening comprehension, but it represents the listener's ability of actively solving problems. This is consistent with the findings of the study conducted by Huang and Naerssen (1987) who found that successful learners were more willing to take risks for employing strategies than less successful learners were. Murphy (1985) discovered that effective listeners used a greater number and range of strategies, while less proficient listeners focused too much on their world knowledge and the text.

The findings of the present study indicated that advanced learners tend to use metacognitive strategies more than socio-affective and cognitive strategies. It can be concluded that advanced learners try to monitor and evaluate their comprehension. These findings are in line with the findings of the study conducted by Chamot and Kupper (1989). They concluded that advanced listeners use metacognitive strategies more frequently, and they monitor their comprehension while doing listening tasks. In another study, Vandergrift (1996) investigated the relationship between listening strategy use and listening proficiency. The study revealed that intermediate listeners employed almost twice as many metacognitive strategies as the novice learners. In addition, advanced learners used twice as many metacognitive strategies as intermediate learners. Peters (1999), in a similar study, elicited listening comprehension strategies of learners with different listening proficiency. She showed that the more skilled listeners used more metacognitive strategies over time (particularly monitoring and evaluation).

This shows the importance of meta-cognitive strategies because, according to O'Malley and Chamot (1990), these strategies regulate and direct the language learning process. However, intermediate language learners employed cognitive, and then social/affective strategies more frequently. Vandergrift (2003) also found that the more skilled listeners preferred to employ meta-cognitive strategies more frequently than the less skilled listeners. However, this does not concur with the study undertaken by O'Malley, Chamot, Kupper Stewner-Manzanares, and Russo (1985). They (1985) believed that the most preferred strategies by intermediate students are meta-cognitive strategies.

The results revealed that intermediate learners tend to employ repetition, resourcing, note-taking, deduction, translation, and other cognitive strategies to comprehend the listening texts. According to O'Malley and Chamot (1990), learners can monitor learning materials and choose particular techniques to a listening task using these cognitive strategies. It was also indicated that social/affective strategies are used more frequently by intermediate group than advanced group. O'Malley and Chamot (1990) suggested that listeners employ socio-affective strategies in order to cooperate with their peers, to lower their anxiety, and to solve their potential problems.

The findings of the present study indicated that there was a relationship between overall listening proficiency of language learners and listening strategies employed by them. To sum up, from a qualitative perspective, the following picture emerges of the relationship between the level of overall proficiency of learners and their choice of strategy. First of all, it was revealed that both groups of listeners appear to be familiar with a wide range of listening strategies, but advanced group appeared to use these strategies more frequently. So, it can be concluded that the level of proficiency is related to the frequency of strategy use. Second, advanced learners use metacognitive strategies more, while the most frequent strategies among intermediate learners are cognitive strategies. Advanced learners are able to control and monitor their comprehension using metacognitive strategies. Third, the use of social/affective by advanced group is not notable, while intermediate learners prefer to use these strategies almost frequently. Therefore, this study showed that students with higher overall proficiency levels employ more listening strategies than less proficient learners, and they tend to use metacognitive strategies more frequently. The finding lends support to the finding by Murphy (1987) who found that more proficient learners use many more specific and a greater number of strategies while interacting with a task than less proficient listeners. O'Malley et al. (1989) also found that there is a difference between the use of listening strategies between more proficient and less proficient listeners. They found that more proficient learners employ a greater variety of listening comprehension strategies. Their study showed that learners with higher proficiency involved more top-down processing, such as self-monitoring and selective attention, than learners with lower proficiency.

The findings of the current study also indicate that intermediate learners tend to use cognitive strategies more frequently. These findings are consistent with the findings of the study conducted by some researchers. For example, Vandergrift (2003) investigated the relationship between listening proficiency and listening strategy used. It was indicated that the most frequent strategies among more skilled listeners were meta-cognitive strategies, and less skilled listeners employed cognitive strategies more frequently than listeners with higher proficiency in listening. 


\section{SUMMARY \& CONCLUSION}

In the current study, an attempt was made to gain insights into the strategies which intermediate and advanced learners of English use in their listening comprehension activities. In addition, it sought to discover the relationship between intermediate and advanced learners' overall proficiency and their choice of strategy.

In order to determine listening strategies used by intermediate and advanced language learners, qualitative data from think-aloud sessions were used. The analysis of data showed that the participants in advanced group employ metacognitive strategies more often. The most frequent metacognitive strategies by these learners are self-monitoring, self-management, and self-reinforcement. However, intermediate learners tend to use cognitive strategies more frequently. The findings of this study are in line with previous findings, suggesting that more skilled listeners employ more metacognitive strategies than less skilled listeners (e.g., O’Malley, Chamot,\& Kupper, 1989; Murphy, 1985). The findings also revealed that intermediate language learners use more social/affective strategies than advanced language learners. The most frequent strategies used by intermediate groups were note-taking and translation.

Descriptive statistics was used in order to answer the final research question which was about the relationship between language learners' overall proficiency and their choice of strategy. The findings showed that there is a relationship between overall listening proficiency of language learners and their choice of listening strategies. So, it can be concluded that the level of proficiency is related to the frequency of strategy use. Furthermore, advanced learners used metacognitive strategies more, while the most frequent strategies among intermediate learners were cognitive strategies. In addition, the use of social/affective strategies by advanced group is not notable, while intermediate learners prefer to use these strategies almost frequently. It was also shown that intermediate learners tend to use cognitive strategies more frequently. These findings are consistent with the findings of the study conducted by some researchers (e.g., Vandergrift, 2003).

\section{REFERENCES}

[1] Chamot, A. U., \& Kupper, L. (1989). Learning strategies in foreign language instruction. Foreign Language Annals, 22 , 13-24.

[2] Chamot, A. U. (2004). Issues in language learning strategy research and teaching. Electronic Journal of Foreign Language Teaching, 1(1), 14-26. Retrieved November 29, 2005, from http://e-flt.nus.edu.sg/.

[3] Cohen, A. D. (2010). Focus on the Language Learner: Styles, Strategies and Motivation. In N. Schmitt (Ed.), An introduction to applied linguistics (pp. 161-178). London: Hodder Education.

[4] Ericsson, A., \& Simon, A. (1984). Protocol Analysis Verbal Reports as Data. Cambridge. Mass: MIT Press.

[5] Gardner, R. C. \& MacIntyre, P. D. (1992). A student's contribution to second-language learning. Part I: Cognitive variables. Language Teaching, 25, 211-220.

[6] Huang, X., \& Naerssen, M. V. (1987). Learning strategies for oral communication. Applied Linguistics, 8, 287-307.

[7] Lessard-Clouston, M. Language Learning Strategies: An Overview for L2 Teachers. I-TESL-J, Retrieved May 5, 2005 from http://iteslj.org/Articles/ Lessard-Clouston-Strategy.html.

[8] Mendelsohn, D. (1998). Teaching listening. Annual Review of Applied Linguistics, 18, 81-101.

[9] Murphy, J. M. (1985). An investigation into the listening strategies of ESL college students. (ERIC Document Reproduction Service No. ED27875).

[10] O'Malley, J. M., Chamot, A. U., \& Kupper, L. (1989). Listening Comprehension Strategies in Second Language Acquisition. Applied Linguistics, 10 (4), 418-437.

[11] O'Malley, J. M., Chamot, A. U. (1990). Learning Strategies in Second Language Acquisition. Cambridge: Cambridge University Press.

[12] Rost, M. (1990). Listening in language learning. London: Longman.

[13] Rubin, J. (1975). What the "Good Language Learner" Can Teach Us. TESOL Quarterly, 9, 41-51.

[14] Vandergrift, L. (1996). Listening strategies of Core French high school students. Canadian Modern Language Review, 52(2), 200-223.

[15] Vandergrift, L. (1999). Facilitating Second language listening comprehension: acquiring successful strategies. ELT Journal, 53(3), 168-176.

[16] Vandergrift, L. (2003). Orchestrating strategy use: Toward a model of the skilled second language listener. Language Learning, 53(3), 463-496.

[17] Wolvin, A. D., \& Coakley, C. G. (1988). Listening (3rd ed.). Dubuque, IA: Wm. C. Brown.

[18] Young, M. Y. C. (1997). A serial ordering of listening comprehension strategies used by advanced ESL learners in Hong Kong. Asian Journal of English language Teaching, 7, 35-53.

Ali Kazemi is an Associate Professor of Applied Linguistics, in the Department of Applied Linguistic at Yasouj University. He received his doctoral degree in Applied Linguistics from the University of New South Wales and Master's Degree in Applied Linguistics from Tarbiat Modarres University. His research interests include language assessment, conversation analysis and L2 pedagogy.

Soraya Kiamarsi holds an M. A. in TEFL. She received both here Master's and B. A. in TEFL from Yasouj University. She is currently teaching English as a Foreign Language. 